\title{
Evaluation of Platelets Count and Indices in Pre-Eclampsia Compared to Normal Pregnancies
}

\author{
Awad-Elkareem Abass ${ }^{1,2}$, Remaz Abdalla $^{1}$, Isra Omer $^{1}$, Salma Ahmed ${ }^{1}$, \\ Ahoud Khalid ${ }^{1}$, Husham Elzein ${ }^{2}$. \\ ${ }^{I}$ (Hematology Department, Faculty Of Medical Laboratory Sciences/ University Of Khartoum, Sudan \\ (Faculty Of Medicine And Applied Medical Sciences/Northern Border University, KSA) ${ }^{2}$
}

\begin{abstract}
Background/Aim: Pre-eclampsia (PE) and eclampsia are major obstetric problem in developing countries and remains an important cause of maternal mortality worldwide. The study aimed to evaluate/compare the platelet count and platelet indices in pre-eclampsia and normal pregnancies

Methods: This prospective case control study was conducted in Khartoum state at Omdurman Maternity Hospital, during the period from March to June 2016. Pregnant women (N/87) with 28 weeks' gestation or more who attended at antenatal care unit or admitted into the Department of Obstetrics and Gynecology, were selected as population of the study. Among them 37 patients with either mild or sever PE, 50 normal pregnancies as controls were enrolled. EDTA-venous blood sample was collected from each patient and control for platelet count and platelet indices measurement by automated blood cells counter (SYSMEX-KX 21).

Results: In the present study the mean platelet counts was $236.16 \pm 82.33,261.34 \pm 62.69 \times 10^{9} / \mathrm{L}$ in patients and controls respectively. The mean MPV was $10.15 \pm 1.10$ and $9.48 \pm 0.87 / f l$, whereas mean $P D W$ was $13.37 \pm 2.84$, $12.15 \pm 2.35 \mathrm{lfl}$ as well as mean $P-L C R \%$ was $26.71 \pm 7.87,22.32 \pm 6.52 \%$ in patients and controls respectively. The present study found that MPV $(P ; 0.02), P D W(P ; 0.03)$ and $P-L C R(P ; 0.05)$ of $P E$ group was significantly higher than normal group. The platelets count $(P ; 0.1)$ and plateletcrit $(P C T \%)(P ; 0.64)$ were lower in $P E$ group but didn't show significant variation.
\end{abstract}

Conclusion: Platelet indices of MPV, PDW and P-LCR increases in PE in comparison to normal pregnancy Key.

Keywords - Eclampsia, Hypertension, Indices, platelets, Pre-eclampsia, Pregnancy.

\section{I.Introduction}

Pre-eclampsia (PE) is a serious multi-systemic pregnancy complication affecting between (5-8 \%) worldwide $[1,2]$. Generally the diagnosis depends mainly on finding of hypertension and proteinuria after 20 weeks of pregnancy [3]. It considered as one of the major health problems associated with pregnancy and one of the causes of maternal mortality $[4,5]$. The prevalence of PE in developing countries ranges from $1.8 \%$ to $16.7 \%$ [6]. In Sudan there is high prevalence of maternal mortality with PE, and accounting $4.2 \%$ of all obstetric complications and $18.1 \%$ of maternal deaths [7]. Although the exact cause of PE is not fully understood, certain factors have been attributed to it which includes changes in placental perfusion, with changes in the coagulation system, endothelial dysfunction, fibrin deposition, and platelet activation $[6,8,9,10]$.

Normal platelets are present in an inactive form in the blood stream and can be activated when became contact with exposed endothelial wall [11,12]. Abnormal active platelets are involved in the pathogenesis of many diseases with thrombotic components like PE [13]. Platelet activity is correlated with change in platelet volume, the larger platelets are haemostaticaly more active and thrombogenic than smaller ones [14]. Mean platelet volume (MPV), Platelet distribution width (PDW), and Platelet-large cell ratio (P-LCR) are volume measuring platelet indices; which increase during platelet activation.

Platelets indices have been recently used in the prediction, diagnosis, and prognosis of many diseases $[15,16,17,18,19]$, being reported as clinically useful biomarkers. The PDW can be a practical tool to evaluate activation of coagulation or thrombocytosis-related disease, and ideal indicators for PE [20]. More recent study have shown that PDW was an ideal indicators for PE [21]. The MPV is the most studied platelet activation marker [22] . It has been noted that MPV increases during pregnancy, particularly in women with PE. Increased MPV occurs before the onset of PE symptoms, therefore, it may be a valuable marker for development of PE $[23,24,25]$. Reduction in platelets count is also observed during the progression of $\mathrm{PE}$, and is suggested to be a characteristic of severe PE [21,26].

In Sudan, most the clinical laboratories are not reported/or evaluated the platelet indices because of unawareness about their availability and clinical importance [27]. Thus, the study aimed to evaluate the platelets count and indices in a group of Sudanese pregnant women with PE and compared them with normal pregnancies. 


\section{II.Material And Methods}

This case control study was conducted in Omdurman Maternity Hospital- Omdurman during the period of March 2016 to June 2016. Women with pregnancy of 28 weeks or more who visited at antenatal care unit or admitted into the Department of Obstetrics and Gynaecology, were enrolled in the study. Participants (N/87) were divided into two groups; PE group as patients(N/37), and normal pregnancy group as controls(N/50). The Demographic and clinical data of each participant were recorded in a pre-designed a questionnaire.

Patients with either mild or sever PE were diagnosed according to the standard diagnostic criteria. Mild $\mathrm{PE}$ was defined as new onset of blood pressure $\geq 140 / 90 \mathrm{mmHg}$, combined with proteinuria $\geq 0.3 \mathrm{~g} / 24 \mathrm{~h}$. Severe $\mathrm{PE}$ was defined as blood pressure $\geq 160 / 110 \mathrm{mmHg}$, serious proteinuria $(\geq 2 \mathrm{~g} / 24 \mathrm{~h}$ ) and manifestations of multiple organ damage or dysfunction. Patients with pre-existing renal disease, chronic hepatitis, diabetes mellitus, history of anticoagulant drug/oral contraceptive/thrombosis, Immune thropmocytopenia (ITP), known bleeding disorder, and any other disorder affecting the platelets function and number were excluded from the study. Normal pregnancies were all healthy women had a normal obstetric history, with normal blood pressure, and had no proteinuria.

The research protocol was approved by Review Board at Haematology department-Faculty of Medical Laboratory Sciences, Khartoum University. Informed written consent was taken from all participants. General physical and clinical examination was performed at Hospital to obtain information about height, weight, systolic and diastolic blood pressure, oedema, pulse, and else. A 24 hour urine protein was performed as part of routine diagnosis for PE in the Hospital's laboratory.

EDTA- K3 venous blood sample $(3 \mathrm{ml})$ was collected from each subject, mixed gently, and was sent within 30 minutes of collection for laboratory investigation. Platelets count and platelets indices were performed as part of complete blood count by automated blood cell counter, Sysmex KX-21.

The results data was analyzed using Microsoft office and Statistical software 'Statistical Package for Social Science (SPSS) program for windows version 16. Simple T-test was used to compare the platelets count and indices in the entire study groups. The quantitative variables were presented as mean $\pm(\mathrm{SD})$ for each group.

\section{III.Results}

Demographic and clinical data of the study subjects are presented in TABLE 1. The difference in age and gestational age among the studied groups (PE and normal pregnancy) showed no statistical significance (P; $0.22,0.35$, respectively). However, there is significant differences in body mass index (BMI) between two groups (P; 0.01). As expected PE group patients had significantly higher systolic and diastolic blood pressure than healthy pregnant women (P; 0.00001, 0.00001), TABLE 1.

There were also significant differences in the platelets indices of MPV, PDW, and P-LCR among the study groups ( $\mathrm{p} ; 0.02,0.03,0.05$, respectively). However, the platelets count and plateletcrit (PCT) didn't vary significantly between PE and normal pregnancy group (P; 0.1, 0.6), TABLE 2.

The mean \pm SD platelet counts and PCT of the PE group were lower than normal group; $236.16 \pm 82.33$ and $0.25 \pm 0.08$ versus $261.34 \pm 62.69$ and $0.26 \pm 0.06$, respectively. The mean \pm SD of MPV, PDW, and P-LCR in $\mathrm{PE}$ group were higher than normal group; $10.15 \pm 1.10,13.37 \pm 2.84$ and $26.71 \pm 7.87$ versus $9.48 \pm 0.87$, $12.15 \pm 2.35$ and $22.32 \pm 6.52$ (TABLE. 2). Thrombocytopenia was present more in $12 / 37(32.4 \%)$ of PE than normal pregnant women $(0.0 \%)$.

Table 1.Means \pm SD Of Demographic/Clinical Data Of Study Population (N/87).

\begin{tabular}{|c|c|c|c|}
\hline Variable & $\begin{array}{c}\text { PE Pregnancy } \\
(\mathrm{N} / 37)\end{array}$ & $\begin{array}{c}\text { Normal Pregnancy } \\
(\mathrm{N} / 50)\end{array}$ & P. value \\
\hline Age/y & $29.08 \pm 6.74$ & $27.50 \pm 5.43$ & 0.22 \\
\hline Gestation age//Week & $33.10 \pm 4.10$ & $34.72 \pm 2.92$ & 0.35 \\
\hline Systolic B.P/mmHg & $158.62 \pm 20.21$ & $107.06 \pm 12.11$ & $<.00001^{*}$ \\
\hline Diastolic B.P/mmHg & $102.72 \pm 12.69$ & $68.62 \pm 9.01$ & $<.00001^{*}$ \\
\hline BMI $\left(\mathrm{Kg} / \mathrm{M}^{2}\right)$ & $27.70 \pm 3.80$ & $25.75 \pm 3.52$ & $0.01^{*}$ \\
\hline
\end{tabular}

Table 2. Means \pm SD Of Platelet Counts and Indices Of Study Population (N/87).

\begin{tabular}{|c|c|c|c|}
\hline Variable & $\begin{array}{c}\text { PE Pregnancy } \\
(\mathrm{N} / 37)\end{array}$ & $\begin{array}{c}\text { Normal Pregnancy } \\
(\mathrm{N} / 50)\end{array}$ & P. value \\
\hline Platelet X10 $/ \mathrm{L}$ & $236.16 \pm 82.33$ & $261.34 \pm 62.69$ & 0.1 \\
\hline MPV/fl & $10.15 \pm 01.10$ & $9.48 \pm 00.87$ & $0.002^{*}$ \\
\hline PDW/fl & $13.37 \pm 02.84$ & $12.15 \pm 02.35$ & $0.03^{*}$ \\
\hline P-LCR\% & $26.71 \pm 07.87$ & $22.32 \pm 06.52$ & $0.005^{*}$ \\
\hline PCT\% & $0.26 \pm 00.06$ & $0.25 \pm 00.08$ & 0.64 \\
\hline
\end{tabular}




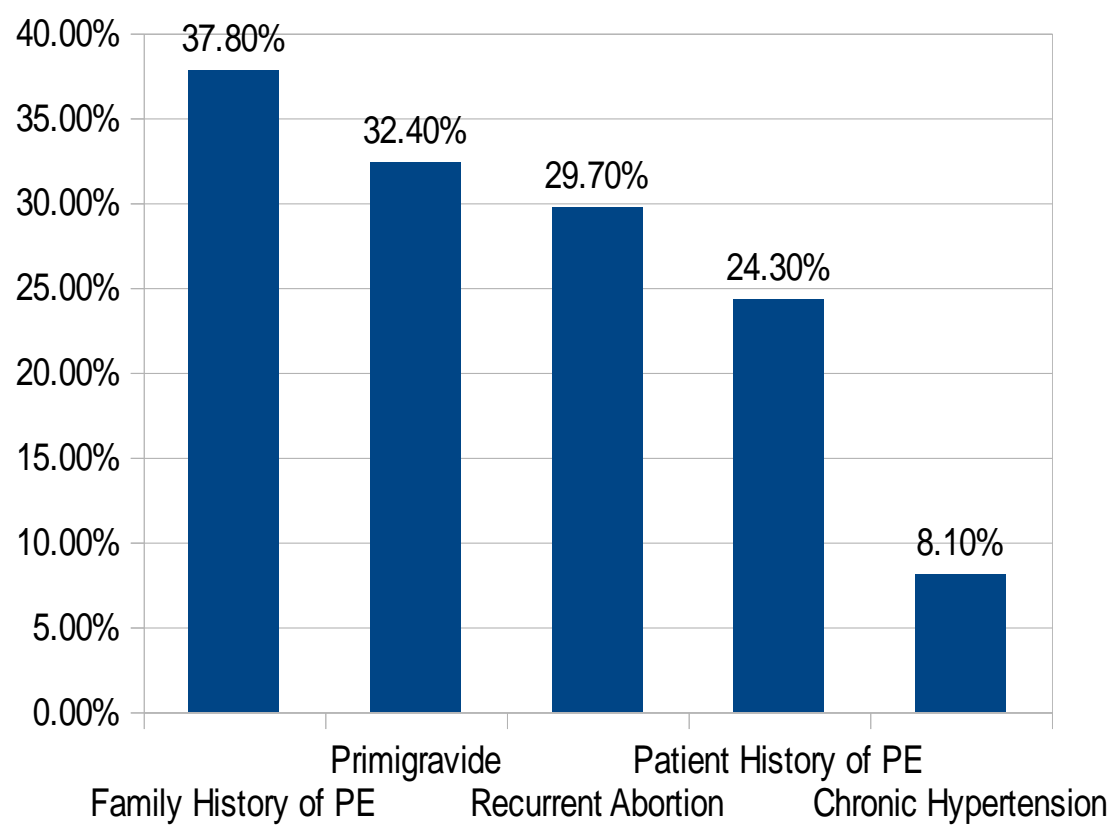

Fig. 1: Maternal Characteristic And Clinical Data In PE (N/37)

\section{IV.Discussion}

PE and eclampsia remains one of the causes of perinatal mortality and maternal death in most developing countries. Many theories suggested that placental change is one of the critical issue in the pathogenesis of PE [suggested that platelet activation begins at initial duration of pregnancy in women with risk for PE [11].

This study compared platelet count and indices among two groups of pregnant women; preeclamptic group (either mild or sever) and normal pregnancy. The present study revealed mean platelet counts of the PE group were lower than normal group, thrombocytopenia were observed in about third of the total included cases of PE. Mohammed et al, (2012) analyzed blood sample of 60 cases of PE and eclampsia and found that the platelet counts were lower in PE and eclampsia group than control group. Also they found that eclampsia group had significantly decreased platelets when compared to the control group or PE groups. They observed marked decline in platelets in PE and eclampsia groups and this decline was directly proportional to the severity of the hypertension [28]. Dadhich et al, (2012) also found decreased platelet count in patients with PE compared to normal pregnancy [29]. Mohapatra and associates (2007) included 30 normal pregnant women and 90 pregnant women with varying degree of pregnancy induced hypertension. They observed that platelet numbers were inversely related to the severity of pregnancy induced hypertension [30].

This study revealed that mean MPV, PDW and PLCR of PE group was significantly higher than normal pregnancy group. These findings were consistent with several studies [29, 31, 32, 33]. Vagdatli et al, (2010) explained that larger platelets create increased MPV, increased PDW and P-LCR [20].

In this study, some of the included cases of PE either had a history of PE, family history of PE, history of recurrent abortion or chronic hypertension; such confounding factors could be a contributor for risk of PE. Our study had limitations of small sample size; further large scale study should be conducted to evaluate the platelets count and indices in such pregnancies. However, investigation of platelets count and indices might serve as useful biomarkers in predicting those PE patients at higher risk for development of disseminated intravascular coagulation ( DIC).

\section{V.Conclusion}

Platelet count decreased and MPV, PDW and PLCR were increased in PE than normal pregnancies.

\section{Acknowledgements}

Authors would like to thank all pregnant womens who were enrolled in this study both patients and controls 


\section{References}

[1]. Sibai B, Dekker G, Kupferminc M. Preeclampsia. Lancet, 365, 2005, 785-799.

[2]. Stekkinger E, Zandstra M, Peeters LL, Spaandernen ME. Early-onset preeclampsia and the prevalence of postpartum metabolic syndrome. Obstet Gynaecol, 114(5), 2009, 1076-1084.

[3]. Semenovakaya Z and Erogul M. Pregnancy, Preeclampsia. eMedicine - Medical Reference, 2010, http://emedicine.medscape.com/article/796690-overview.

[4]. Khan KS, Wojdyla D, Say L, Gülmezoglu AM, Van Look P. WHO analysis of causes of maternal death: a systemic review. Lancet, 367(9516), 2006,1066-1074.

[5]. Duley L. The global impact of pre-eclampsia and eclampsia. Semin Perinatol, 33, 2009, 130-137.

[6]. Osungbade KO and Ige OK. 'Public Health Perspectives of Preeclampsia in Developing Countries: Implication for Health System Strengthening. J of Preg, 2011, Article ID 481095.

[7]. Ali AA, Okud A, Khojali A, Adam I. High incidence of obstetric complications in Kassala hospital, eastern Sudan. J Obstet Gynaecol, 32(2), 2012, 148-149.

[8]. Roberts J, Gammil H. Preeclapsia: recent insight. Hypertension, 46(6), 2005, 1243-1249.

[9]. Fernando A, Daftary SN, Bhide AG. Hypertensive disorders in pregnancy. Practical guide to high risk pregnancy and delivery. $3^{\text {rd }}$ ed. New Delhi: Elsevier, 2008, p. 411.

[10]. Redman CW, Sargent IL. Placental stress and pre-eclampsia: a revised view. Placenta, 30, 2009, 38-42.

[11]. Vladareanu AM, Andrei C, Onisai M, et al. The endothelial-platelet dysfunction in preeclampsia. Maedica- J of Clin Med, 2(3), 2007, 214-221.

[12]. Holthe MR, Staff AC, Berge LN, Lyberg T. Different levels of platelet activation in preeclamptic, normotensive pregnant, and nonpregnant women. Am J Obstet Gynecol, 190, 2004, 1128-34.

[13]. M K Goshal, M Bhattecharyya. Overview of Platelet Physiology: Its Hemostatic and Nonhemostatic Role in Disease Pathogenesis. The Scien World J, 2014, 1-16.

[14]. Ranjith MP, Divya R, Mehta VK, Krishnan MG, Raj RK, Kavishwar A. 'Significance of platelet volume indices and platelet count in ischaemic heart disease. J Clin Pathol, 62, 2009, 830-833.

[15]. Bowels KM, Cooke LJ, Richards EM \& Baglin TP. Platelet size has diagnostic predictive value in patients with thrombocytopenia. Clin Lab Haem, 27, 2005, 370-373.

[16]. Song YH, Park SH, Kim JE, et al. Evaluation of platelet indices for differential diagnosis of thrombocytosis by ADVIA 120. Kor J Lab Med. 29(6), 2009, 505-509.

[17]. Cremer M, Paetzold J, Schmalisch G, et al. Immature platelet fraction as novel laboratory parameter predicting the course of neonatal thrombocytopenia. Brit J Haem, 144(4), 2009, 619-621.

[18]. Kaito K, Otsubu H, Usui N, et al. Platelet size deviation with, platelet large cell ratio, and mean platelet volume have sufficient sensitivity and specificity in the diagnosis of immune thrombocytopenia. Brit J Haem, 128, 2005, 698-702.

[19]. Awad-Elkareem Abass, Thuwaiba Yassir, Yasmeen Saeed, et al. Investigation of platelets count and indices in coronary artery diseases among Sudanese patients. IOSR J of Dent and Med Scien, 15(1), 2016, 35-38.

[20]. Vagdatli, E., Gounari, E., Lazaridou, E., et al. Platelet Distribution Width: A Simple, Practical and Specific Marker of Activation of Coagulation. Hippokratia, 14, 2010, 28-32.

[21]. Yang SW, Cho SH, Kwon HS, Sohn IS, Hwang HS. Significance of the platelet distribution width as a severity marker for the development of preeclampsia. Eur J Obstet Gynecol Reprod Biol, 175, 2014, 107-111.

[22]. Coban E, Yazicioglu G, Avci A Berkant, Akcit F. The mean platelet volume in patients with essential and white coat hypertension. Platelets, 16, 2005, 435-438.

[23]. Dundar, O., Yoruk, P., Tutuncu, L., et al. Longitudinal Study of Platelet Size Changes in Gestation and Predictive Power of Elevated MPV in Development of Preeclampsia. Prenatal Diag, 28, 2008, 1052-1056.

[24]. Järemo, P., Lindahl, T.L., Lennmarken, C., et al. The Use of Platelet Density and Volume Measurements to Estimate the Severity of Preeclampsia. Eur J of Clin Invest, 30, 2000, 1113-1118.

[25]. Ceyhan, T., Beyan, C., Baser, I., et al. The Effect of Preeclampsia on Complete Blood Count, Platelet Count And Mean Platelet Volume. Annals of Hematology, 85(5), 2006, 320-322.

[26]. De Vivo A, Baviera G, Giordano D, et al. Endoglin, PlGF and sFlt-1 as markers for predicting pre-eclampsia. Acta Obstet Gynecol Scand, 87, 2008, 837-842.

[27]. Awad-Elkareem Abass, Israa Ismail, Razaz Yahia, et al. Reference Value of Platelets Count and Indices in Sudanese Using Sysmex KX-21. Inter J of Heal care Scien,3 (2), 2015, 120-125.

[28]. Vladareanu AM, Andrei C, Onisai M, Vasilache V, Bumbea H, Vladareanu R, Bumbea H. The endothelial-platelet dysfunction in preeclampsia. Maedica- A J of Clin Med, 2(3), 2007, 214-221.

[29]. Dadhich S, Agrawal S, Soni M, et al. Predictive value of platelet indices in development of preeclampsia' J South Asian Feder Obst Gynae, 4(1), 2012, 17-21.

[30]. Mohapatra S, Pradhan BB, Satpathy UK, Mohanty A and Pattnaik JR. Platelet estimation : its prognostic value in pregnancy induced hypertension. Indian j Physiol Pharmacol, 51(2,) 2007, 160-164.

[31]. Piazze, J., Gioia, S., Maranghi, L and Aneshi, M. Mean platelet and red cell volume measurement to estimate the severity of hypertension in pregnancy. Perinat Med, 34, 2006, 246-247.

[32]. Biva Rani Mondal 1, Debatosh Paul 2, Tuhin Sultana 3 ,et al,Assessment of platelet count and platelet indices in pre-eclampsia and eclampsia. The Amer J of Innov Res and Appl Scien, 1(3), 2015, 80-84.

[33]. Han L, Liu X, Li H, Zou J, Yang Z, et al. Blood Coagulation Parameters and Platelet Indices: Changes in Normal and Preeclamptic Pregnancies and Predictive Values for Preeclampsia. PLoS ONE, 9(12), 2014, e114488. 